POR 00443

\title{
The anterior cricoid split in puppies
}

\author{
John W. Babyak, Peter P. Passamani and Michael J. Sullivan \\ Department of Otolaryngology - Head and Nack Surgery, The University of Michigan, Ann Arbor, \\ MI (U.S.A.) \\ (Received 16 April 1987) \\ (Accepted 21 May 1987)
}

Key words: Anterior cricoid split, Cricoid cartilage; Intubation injury

Summary

The acute and long-term effects of the anterior cricoid split on the subglottis of puppies intubated from 7 to 14 days are documented. The anterior cricoid split acutely increased the intralumenal cricoid surface area in puppies with intubationinduced airway injury. An intense inflammatory response with mucosal ulceration and granulation tissue is elicited by 14 days of intubation by using the canine model of induced subglottic stenosis developed by Supance et al. [19]. When animals intubated for 14 days underwernt an anterior cricoid split on day $i$, the airway appears essentially normal by day 14 . The split cricoid cartilage maintained a ' $U$ ' configuration following the proceilure. The regior of deficient cartilage anteriorly is bridged by fibrous tissue with normal epithelum lining the lumenal surface. Splitting the cricoid cartilage anteriorly increased the intralumenal area and no long term complications resulted from the procedure. The mechanisms by which the anterior cricoid split expands the airway intralumenal area while maintaining airway support have been reviewed.

\section{Introduction}

The infant mortality rate (deaths of children under one year of age per 1000 live births) had declined steadily over the past 15 years. Advances in respiratory support of neonates have probably been the single most ismportant factor for this decline. These advances have relied increasingly on mechanical respiratory support for

Correspondence: J.W. Babyak, Department of Otolaryngology-.-Heaủ and Neck Surgery, Box 0312, Taubman Medical Center, University of Michigan, 1500 East Medical Center Drive, Ann Arbor, MI 48109-0312, U.S.S.A. 
immature infants with ventilatory failure. Prolonged intubation is generally well tolerated by reonates without significant morbidity or sequelae. However, potentialiy severe complications sich as subglottic stenosis occasionally result from this form of treatment. Extubation is often difficult in these patients and a tracheostomy is often required for adequate ventilation.

In 1980, Cotton and Seid proposed the anterior cricoid split as an alternative to tracheotomy in the managem ?nt of extubation problems in the premature child [3]. Several years later, Frankel et al. [7] described the use of the anterior cricoid splii operation in infants with acquired subgiottic stenosis. Holinger [11] recently reviewed his own experience as well as the reported cases utilizing the anterior cricoid split procedure. He concluded that a tracheotomy can be avoided in properly selected cases.

Several mechanis:as have been proposer to explain the success of the anterior cricoid split. This study utilized a modification of a canine model of subglottic injury proposed by Supance [19]. The study elucidates the short- and long-term effects of the anterior cricoid split on an acutely injured canine larynx.

\section{Methods}

Twenty-four healthy, mongrel puppies 5-10 weeks of age were obtained from regional kennels and randomly assigned to 6 study groups. The average weight of the animals was $2.72 \mathrm{~kg}$ (range 1.6-4.5 $\mathrm{kg}$ ). The average weight of the animals in each group was similar. The puppies were conditioned and housed at the University Medical Affiliates Animal Care Facility. Each animal was vaccinated against DHLP and PV (0.1 ml $\times 4$ doses). The caloric intake and weight of each animal was closely monitored daily.

All of the animals were intubated under general anesthesia. Atropine (0.09 $\mathrm{mg} / \mathrm{kg})$ i.m. and Acepromazine $(0.55 \mathrm{mg} / \mathrm{kg}$ ) i.m. were used prior to the induction of general anesthesia with i.v. pentobarbital sodium $(13.2 \mathrm{mg} / \mathrm{kg})$. An uncuffed endotracheal tube (polyvinyl chloride) was placed after direct visualization of the endolarynx. The largest tube which permitted an air leak with a $20 \mathrm{~cm}$ positive pressure ventilation was chosen. The animals were then mechanically ventilated using oxygen and methoxyflurane.

Under sterile conditions, a vertical, midline neck incision was made exposing the upper 3-4 tracheal rings. The anesthesia was lightened to allow the animals to breathe spontaneously and the endotracheal tube was removed. This tube was replaced with a $4 \mathrm{~cm}$ segment of endotracheal tube placed endoscopically into the laryngotracheal complex with the superior aspect $5 \mathrm{~mm}$ above the vocal cords (Fig. 1). The tube was secured in place using a 3-0 prolene suture through the xposed trachea. The subcutaneous tissue and skin were closed. The animals were awakened with the endotracheal tube fixed in position in the laryngotracheal complex.

The puppies were randomized to one of 6 groups. Each group had 4 animals.

Group I - intubated 7 days

Group II - intubaied 14 days 

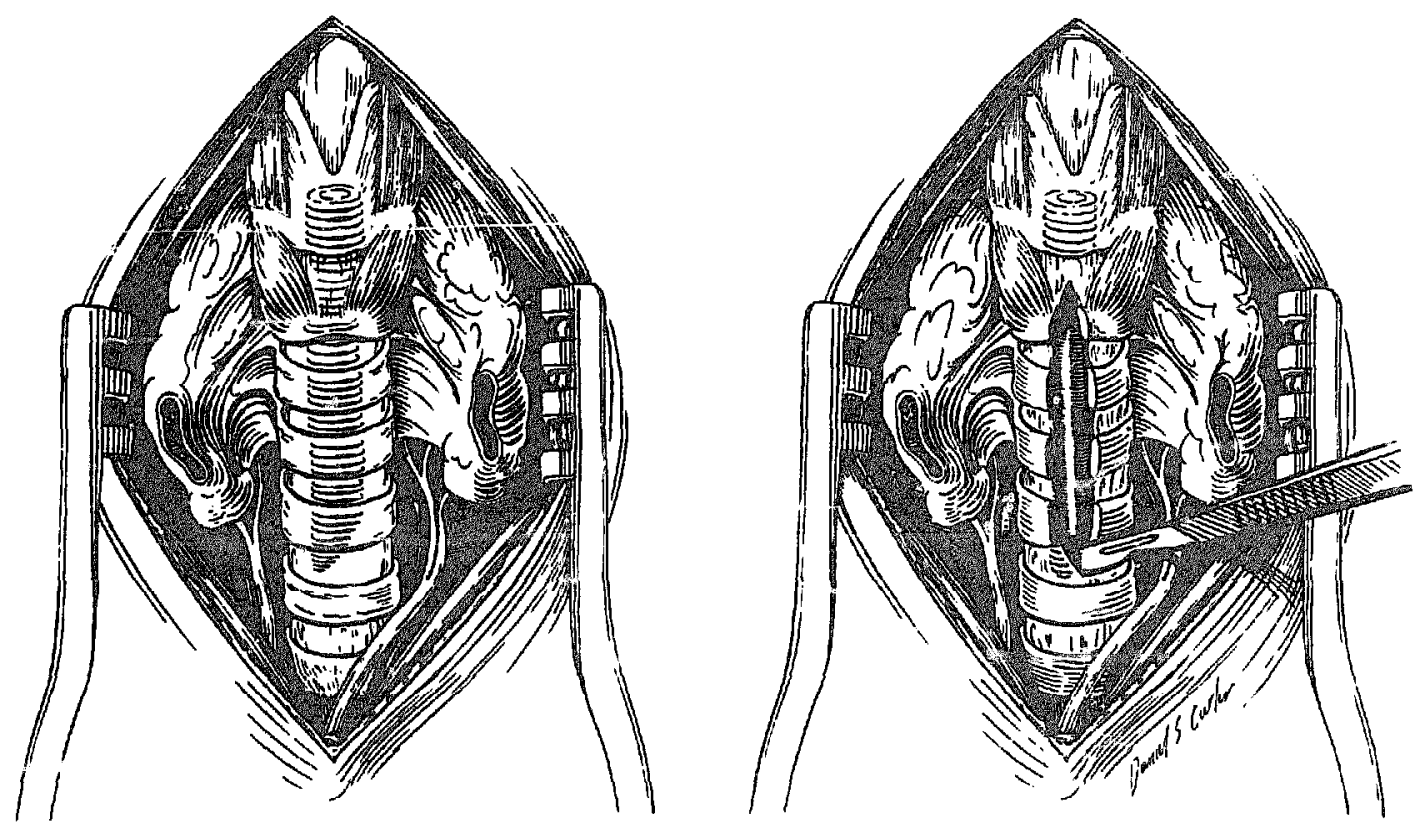

Fig. 1. Artist sketch of the positioning of the endotracheal tube segmenc extending from $5 \mathrm{~mm}$ above the glottis into the trachea.

Fig. 2. Incision of the midline through the cricoid cartilage and upper tracheal rings.

Group III - intubated 7 days; anterior cricoid split on day 7

Group IV - intubated 14 days; anterior cricoid split on day 7; extubated and sacrificed day 14

Group V - intubated 14 days; anterior cricoid split on day 7; extubated day 14 and sacrificed day 31

Group VI - intubated 14 days; anterior cricoid split day 7; extubated day 14; sacrificed at 6 months of age.

Animals in Groups III, IV, V, VI had an anterior cricoid split performed. The anterior cricoid split was performed under local anesthesia, $2 \%$ lidocaine, after i.m. sedation with Innovar Vet $(0.4 \mathrm{mg}$ fentanyl $/ 20.0 \mathrm{mg}$ droperidol per ml), $1 \mathrm{ml}$ per $6.8 \mathrm{~kg}$. Under sterile conditions the cricoid cartilage and upper two tracheal rings were split in the midine (Fig. 2). The incision extsided through mucesa exposing the indwelling segmeni of endotracheal tube. The neck skin was then loosely approximated for the closurc. The animals in each group were extubater and sacrificed at a specific time. The laryngotracheal complexes were sectioned, photographed and submiated for histologic examination. The acute increase in intralumenal cricoid surface srea resulting from performing the anterior cricoid spiit was measured in Group III animals. The dogs in Group III were sacrificed immediately after performing the anterior ericcid split. The laryngotracheal cumplex was harvested und the cricoid cartilage intralumenal area in the 'open' position was measured with a polar planimeter. The anterior extent of the cirway lumen was defined by a line drawn between the posterior edges of the divided cricoid cartilage. 
The cut ends of the cricoid cartilage were then re-approximated and the cricoid cartilage intralumenal area in its 'closed' position was measured. The area difference represented the change in intralumenal area created by the cricoid split.

\section{Results}

\section{Group I-intubsted 7 days}

The animals in this group tolerated 7 days of intubation without difficulty. Coughing and occasional aspiration subsided in each of the animals after the initial 24-48 h of intubation.

Following 7 days of intubation, the subglottic mucosa grossly appeared erythematous and mildly edematous (Fig. 3). There were areas of superficial mucosal ulceration.

Microscopically, the specimens displayed submucosal inflammation and edema, acute mucositis with inflammatory changes in the minor salivary glands. Small areas of superficial epithelial ulceration were aiso present.

\section{Group II-intubated 14 days}

Whereas the initial 10-12 days of intubation were tolerated without difficulty, following the 12th day of intubation the oral intake dropped off considerably. One

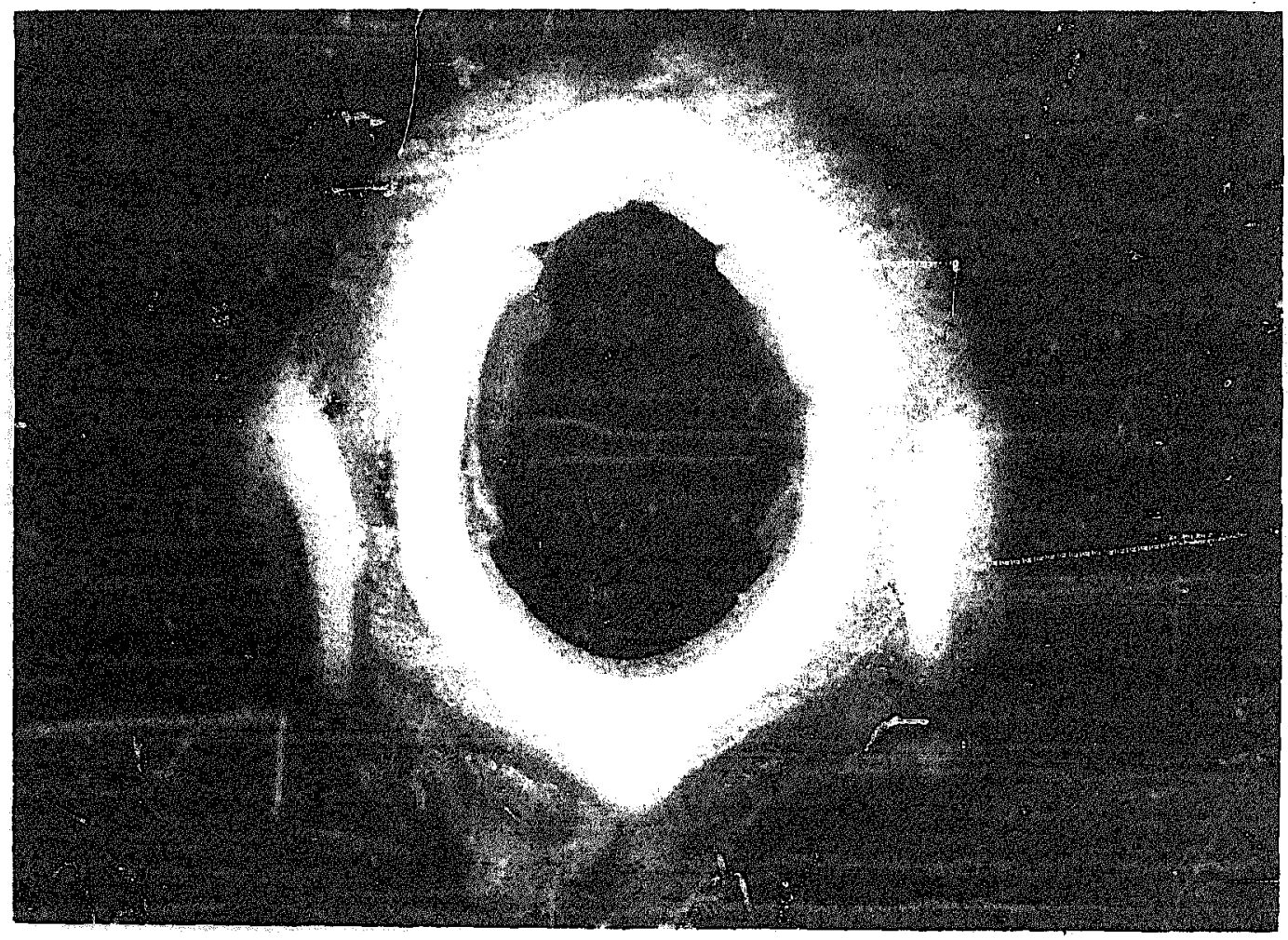

Fig. 3. Section through cricoid cartilage intubated for 7 days. Minimal mucosal edema $(\times 3)$. 


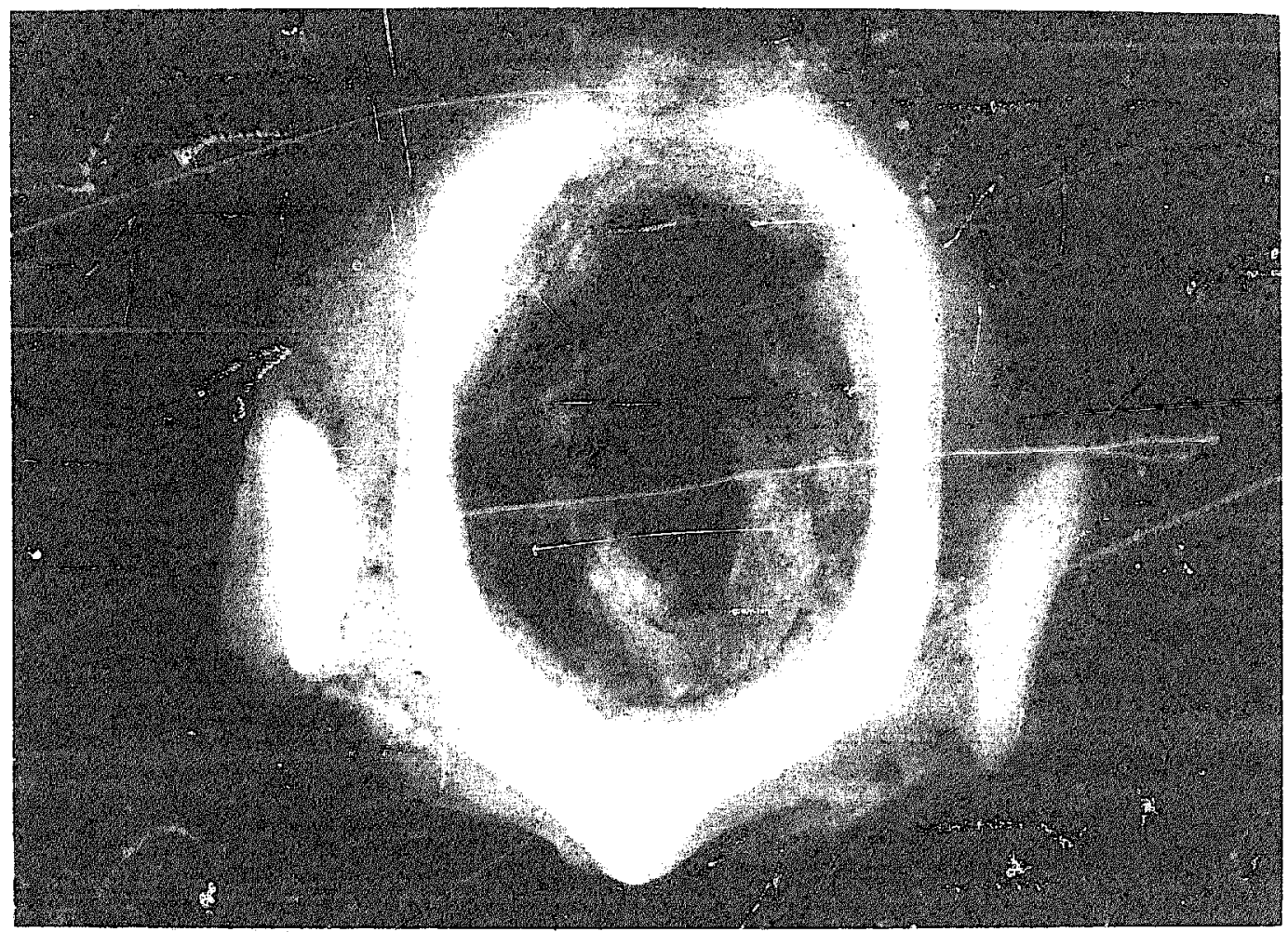

Fig. 4. Section through cricoid cartilage intubated for 14 days. Airway lumen narrowed by extensive granulation tissue $(\times 3)$.

animal in this group was sacrificed on day 11 because of fulminant enteritis. The animals were extubated for approximately $1 \mathrm{~h}$ prior to being sacrificed. Marked inspiratory and expiratory stridor was present but the animals maintained adequate ventilation.

Grossly, the subglottic region in the animals intubated for 14 days was filled with pink, soft granulation tissue which narrowed the airway lumen (Fig. 4). Multiple areas of exposed cricoid cartilage were also observed.

Microscopically, a chronic inflammatory response characterized by a mononuclear cell infiltration was present. The granulation tissue displayed fibroblast proliferation and blood vessel ingrowth in a loose, edematous matrix. Perichondritis was evident in the areas of exposed cartilage.

Group III--intubated 7 days. Anterior cricoid split day 7

The cricoid cartilage 'sprung open' $3.0-8.0 \mathrm{~mm}$ following the anterior cricoid split on the 7th day (Fig. 5). In one of the animals, the endotracheal tube was removed immediately before performing the anterior cricoid split but the cricoid opened in a similar fashion as those animals in which the endotracheal tube was present (Fig. 6). The animals were sacrificed and the intralumenal cricrid area was measured with a polar planimeter. A second measurement was taken after the cut ends of the cricoid were re-approximated (Fig. 7). The area with the cricoid cartilage 


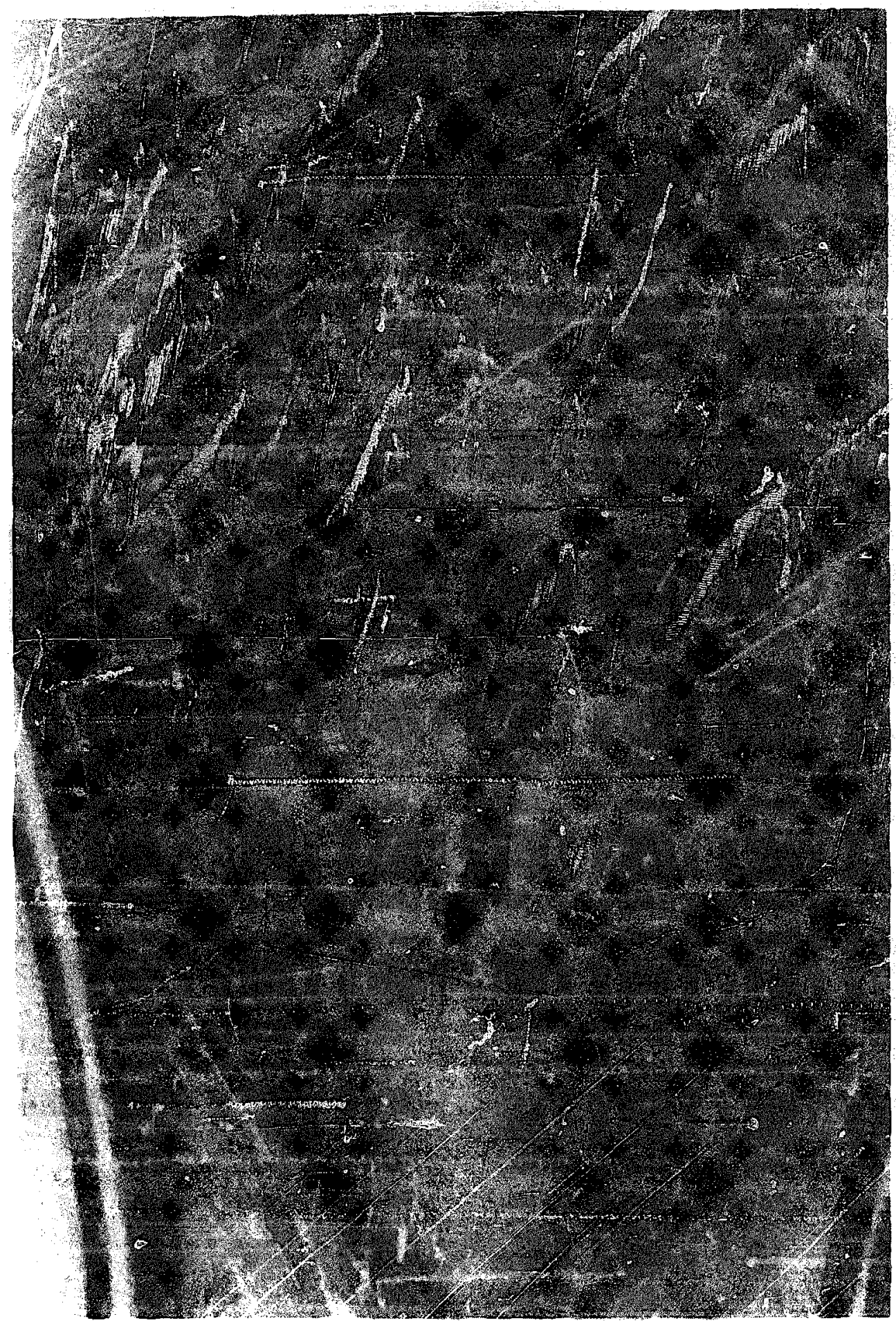

Fig. 5. Intra-operative photogcauh of a aryngotracheal complex intubated 7 days innmediativy after performing the axterior cricoid split. Endotracheal tube segment present in the airway lumen. A.rows point to the cricoid cartilage. Note how th: cut ends of the cricoid and tracheal cartilages have 'sprung' opert. 


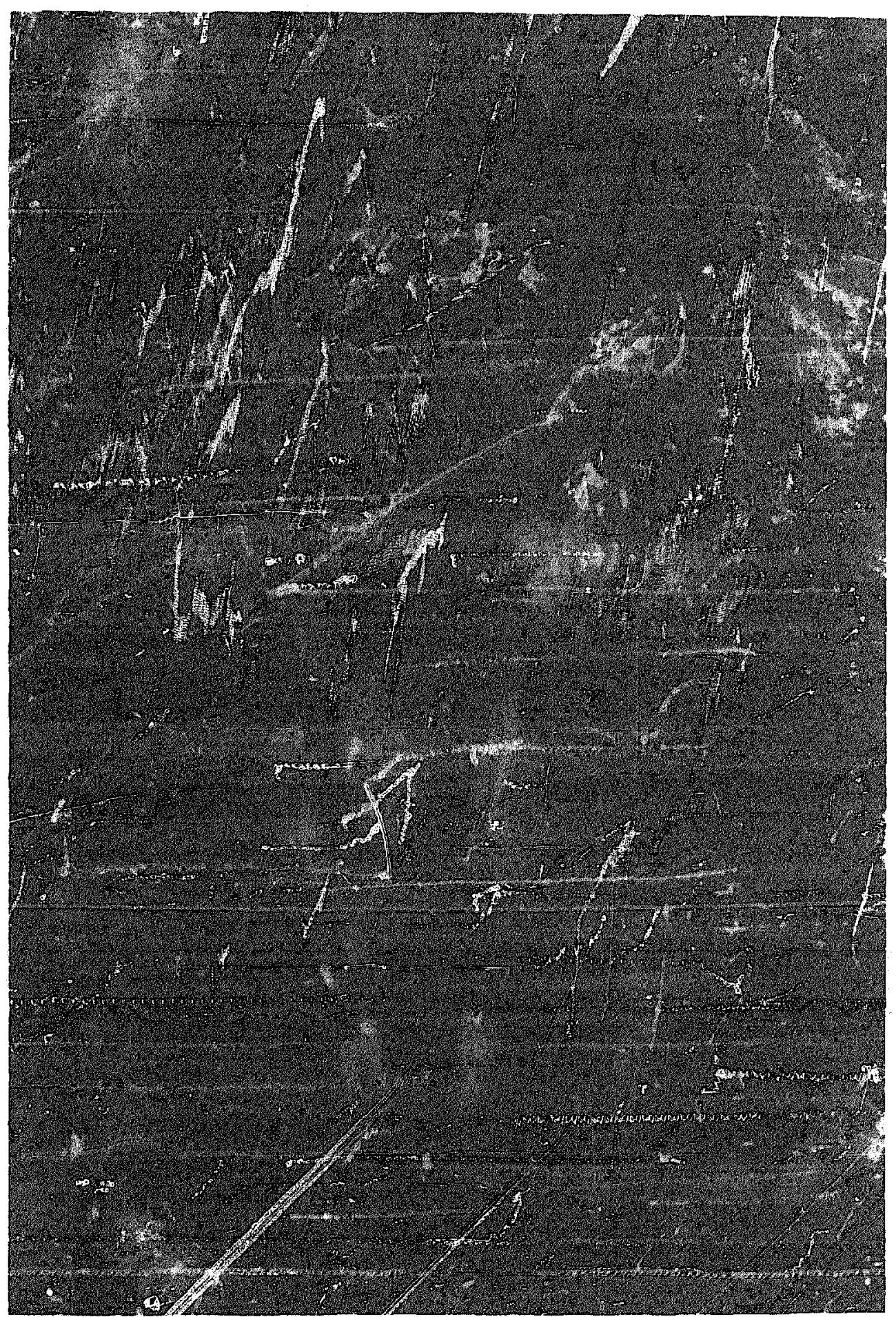

Fig. 6. Intra otsrative photograph of a laryngotracheal comples intubated for 7 days. The eadotracheal tube segmes: was removed prior to performing the anterior cricoid split.

re-approximated was subtracted from the post-split area. The vercent change was then calculated. The oricoid intralumenai area increased in every case with ast average increase, after the procedure of $26 \%$ (range 24-2.). Except for the aciterior 

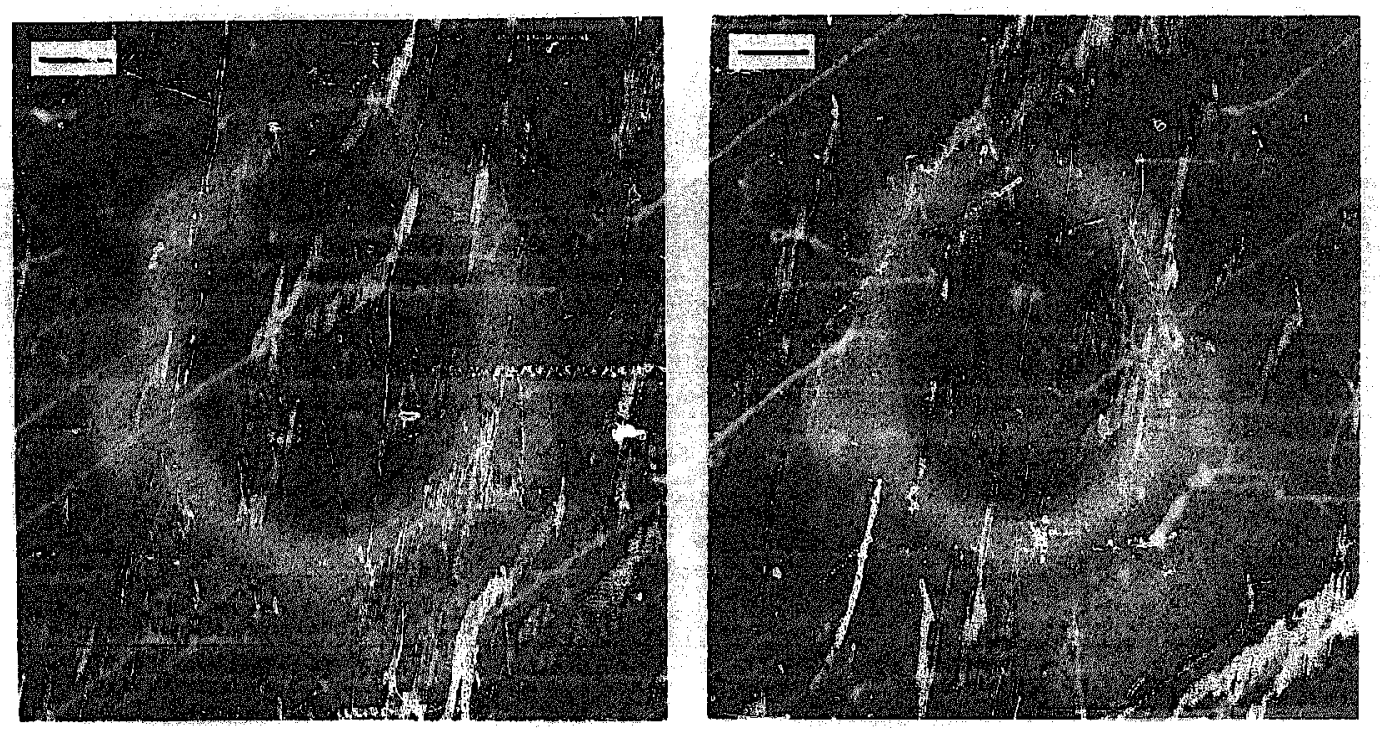

Fig. 7. Sections through cricod cartlage. Left, specimen harvested immediately after parforming the anterior cricoid split. Right, sut siges of the cricoid cairilage re-approximated to calculate the pre-anterior crisoid split intruilumental surface area. (bar $=5 \mathrm{~cm})$.

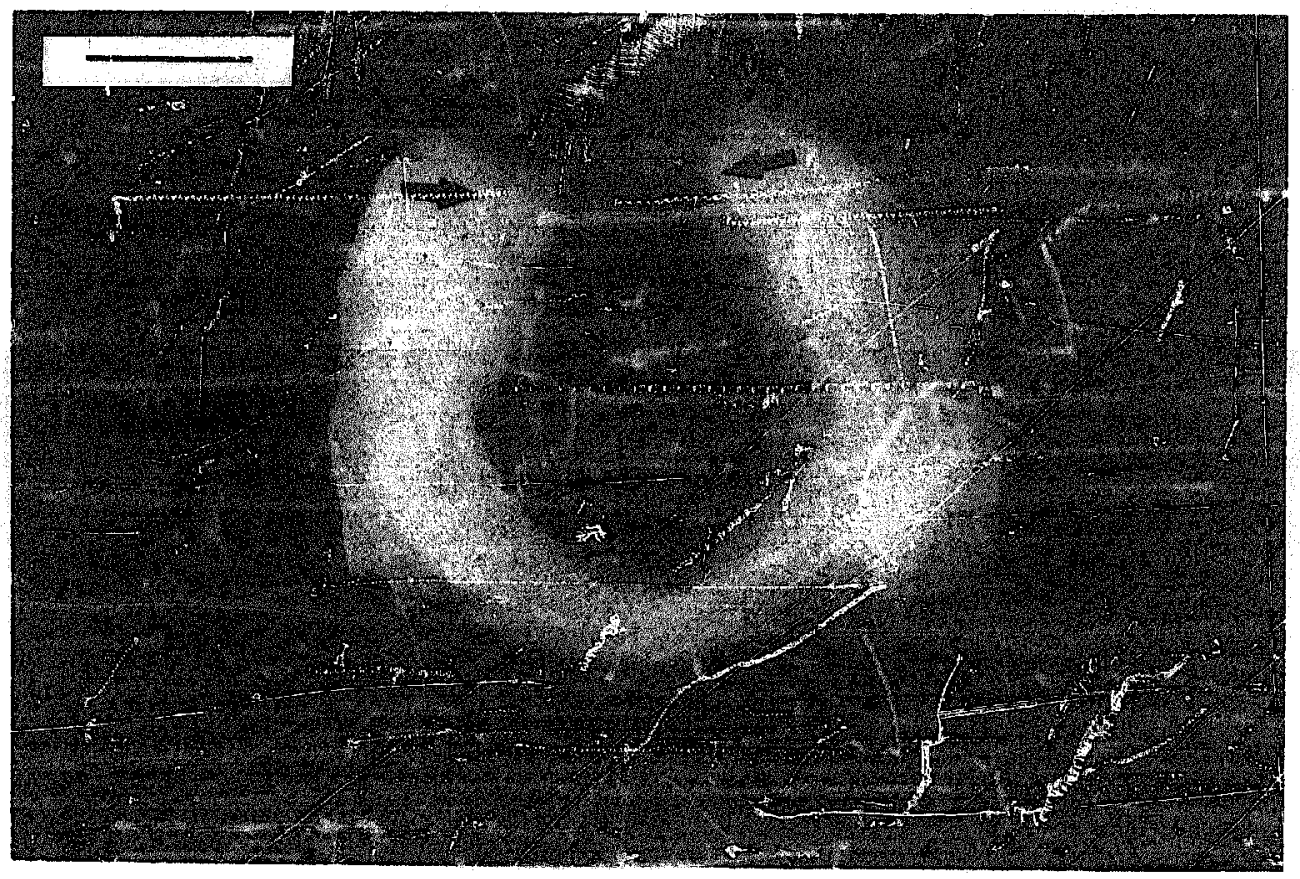

Fig. 8. Section through cricoid cartilage. Specinien 7 days after anterior cricoid split. Granulaticn tissue bet ween cut edges of the cricoid cartilage which does not narrow the airway lumen. Arrows on the cricoid cartilage. (bar $=10 \mathrm{~mm}$ ). 


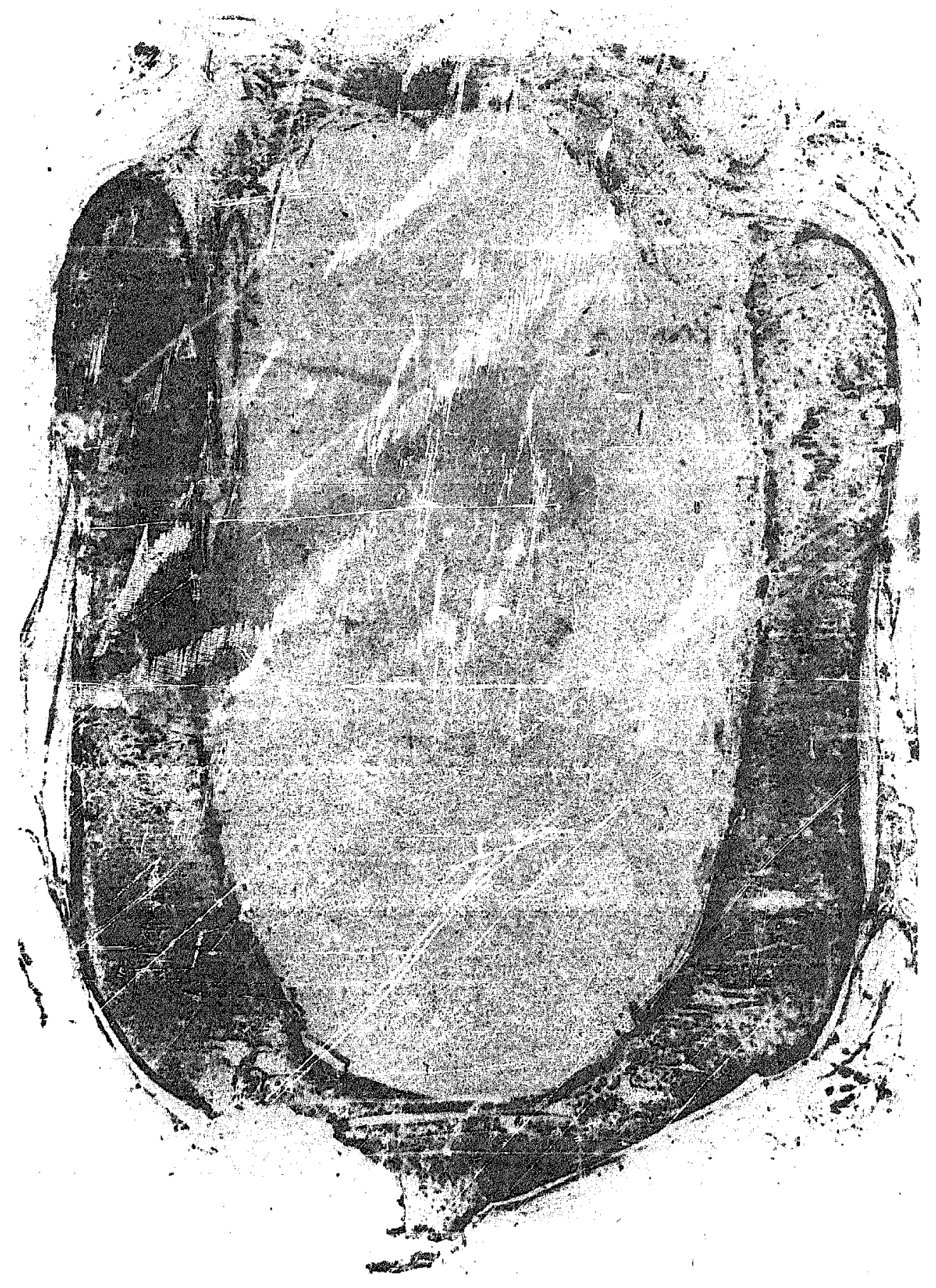

Fig. 9. Deralcified section through cricoid carcilage 6 months after ante ior cricoid split. 'U' configura. tion demonstrated $(\times 6)$. 
cricoid cartilage cut, the gioss and microscopic appearance of the specimens were sizailsar to Group 1 .

Group IV-intubated 14 days. Anterior cricoid split day 7. Extubuted and sacrificed day 14

This group of animals tolerated the endotracheal tube without asy difficulty and gained weight quite rapidly during the stowd week of intubat $n$.

Endoscopically on the 14th day, there was no evidence of laryngoiracheal collapse at the site of the anterior cricoid split.

The subglottis in these animals at hay 14 grossly appeared normal except for minimal mucosal edema. Granulation tissue was present anteriorly between the cut ends of the cricoid cartilage (Fig. 8). In contrast to the subglottis from the animais in Group II who wer not split but intubated for 14 days, grossly the granulation tissue in these puppies was negligible and did not encroach into the airway lumen. Additionally, there wure no areas of exposed carillage in these anisaals.

Microscopically, chronic inflammatory changes were present in the animals but to a lesser degree than in "Group II. Ulceration was absent as wa evidence of perichondritis or chondritis.

Group V-intubated 14 days. Anterior cricoid split day 7. Extubated day 14. Sacrificed day 31

Thte split cricoid cartilage maintained the open configuration without any evi-

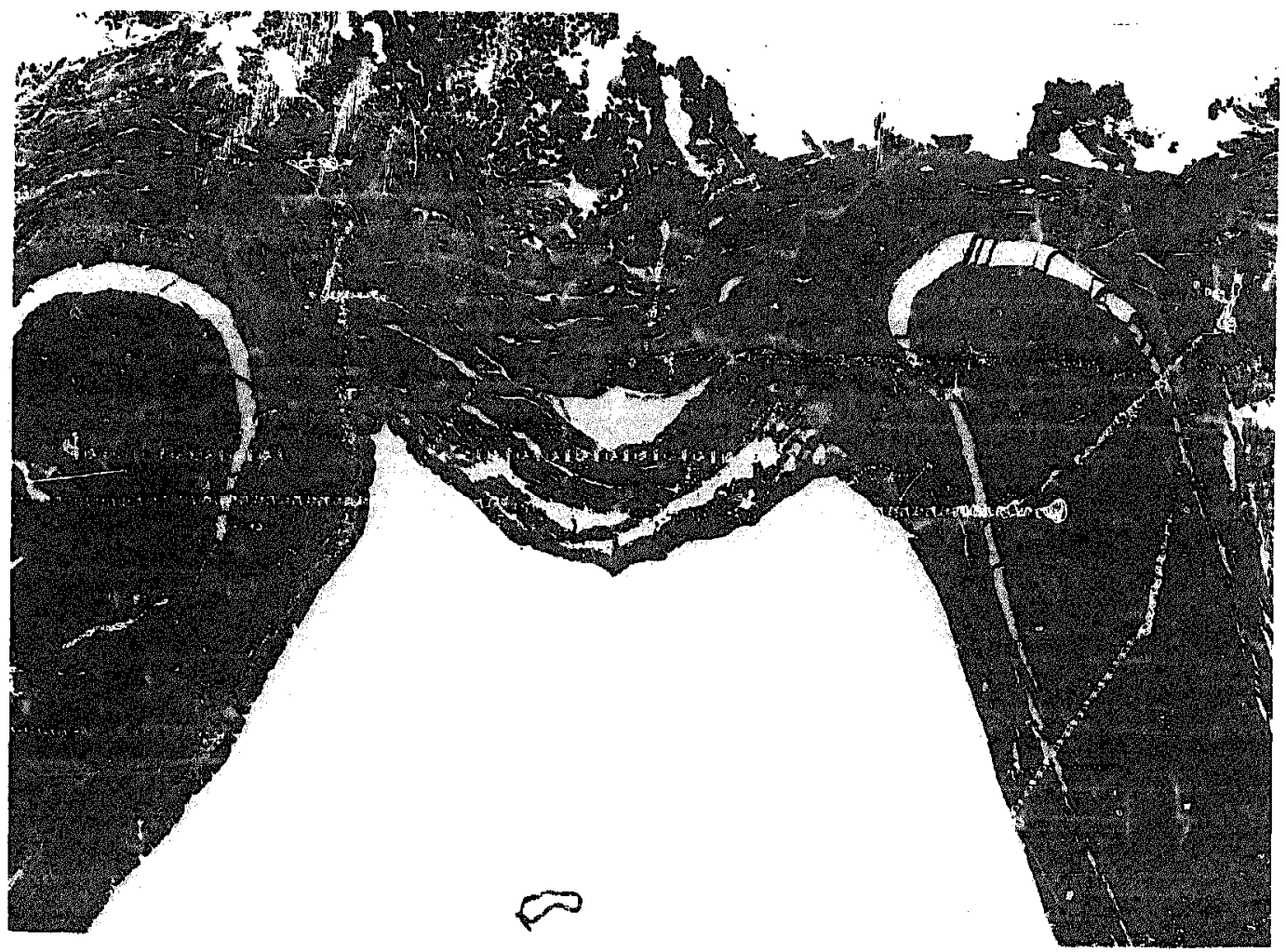

Fig. 10. Photomicrograph of the split cricoid cartilagr and intervening mature scar tissue 6 months after performing the anterior cricoid spli: (H\&E, $\times 50$ ). 
dence of airway granuiation tissue. Microscopically, the rgion between the cut ends of the cricoid cartilage demonstrated the formation of scar tissue with decreased inflammatory cells, decreased vascialarity, and increased collagen frmation. The crir oic lumen was encirely re-epithelialized by this the.

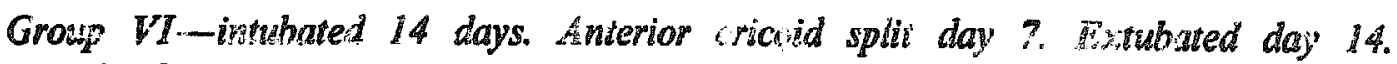
Sacrificed month 6

The laryngotracheal complex in dogs reaches full growth and maturity by 6 months. No long tarm complications were encountered in Gronp $\sqrt{1}$ animais following the anterior cricoid split and extubation. The cricoid catilage maintained the open configuration at 6 morths after anterior cricoid split (Fig. 9). Maiure scar bridged tho gap between the ends of the cricoid cartilage (Fig. 10). Jrossly, seither laryngomalacia tracheomalacia occurred as a result of the proredure.

\section{Disces: ingn}

Over the past 15 years therc has teen a steady decline in lhe infant mortality rate. Factors attributed to the declining rate of infant deaths include the introduction of the Medicaid program, incressed emphasis on prenatal care, and improvid technology in perinatolog:'. Respiratory support has been one of the single mosi important factors contributing to the dramatic decrease in mortality.

Although mechanical ventilation was first used for hyaline membrane disease in 1:53, it was not until the early sixties that it began to be used frequenly [10]. Increased use of merhanical ventilation necessitated a means to manage and maintain the airway on a long term basis. Tracheostomy has for many years been the safest method of securing the airway in these cases. In recent years, however, this philosophy has changed. MeDonald and Stocks, in 1965, advocated prolonged nasotracheal intubation of bahies and children with reversible respiratory inadequacy as an alternative to tracheostomy [14]. Their work provided the foundation for subsequent acceptance of prolonged endotracheal management of the upper airway in neongtes.

As the indications and frequency of nasotracheal and endotracheal support of the airway increased, so did acute and late complications associated with their use. The spectrum of complications range from acute edema and hemorrthge to acquired subglottic stenos is. The incidence of acquired subglottic steno: is following prolonged intubation in neonates and infants has varied from 12 to $20 \%[5,8]$ in the late 1960 's and early 2970 's to ass than $2 \%$ currently $[4,10,18]$. Estimates that up to $45 \%$ of admissions to neonatal intensive care units require intubation for periods longer than 7 days eulphasize the need to develop ways to prevent accuired subglotic stenosis from occurring lo"lowing prolonged intubation [1]

The cricoid cartilage is of central importance in the discussion of airway trauma indwed by prolonged intubation. The subglotic ar ace bounded by the cricoid is the narrowest portion of the airway [6]. The cricoid lumenal disimeter in the full-renu newborn measures $4.5-5.0 \mathrm{~mm}$ [13]. 
As the only complete cartilaginous sing in the upper respiratory tract, the cricoid cartilage is the most common si'e for airway narrowing following injury due to prolonged intubation. The subglottic area is the site of abundant, loose areolar tissue in a submucosal plane that underlies a layer of respiratory epithelium. This collngenous matrix of the submucosa is easily injured and is prone to ulceration and fibrosis. The cricoid cartilage and mucosa are fixed to the larynx above and to the trachea below rendering it susceptible to injury by the pulsion movement of an endotrache wibe. The posterior portion of the larynx is interposed between the cervical vortebrae and the endotracheal tube and acts as a fulcrum, this significant pressure is exerted on the posterior lamina of the cricoid [12].

Airway injury resulting from prolonged intubation is associated with a specifto sequence of events culminating in subglottic stenosis [3]- Initially, mivosal = and hemorrhage are present. The next stage of ulceration can be quite superficial, or as time progresses or infection intervenes, quite extensive and deep. Exposed cartilage results in perichondritis and frank chondritis. Reparative efforts range from epithelial regrowth in cases of minimal damage to the formation of exuterant granulation tissue and subepithelial fibrosis producing dense scars.

Cotton and Seid in 1980 were able to relieve the airway compromise resulting from subglottic narrowing in a group of neonates who were intubated for prolonged periods by vertically incising the cricoid cartilage and upper tracheal rings with mucosa to allow the damaged mucosa and cartilage to 'decompress' [3] Review of the cases reported in the literature.demonstrates that $72 \%$ of the children have been successfully extubated and a tracheostomy avoided by utilizing the anterior cricoid split [1,2,3,7,9,11,15,17].

The indications for performing the anterior cricoid split have recently been expanded to include older children with a history of acquired subglottic stenosis resulting from prolonged intubation who developed progressive sirpay difficulties several months after extubation. Holinger used the term "secondary" anterior cricoid split to describe this distinctly different group of children [11]. These children are successfully extubated in 85 \% of the cases $[1-3,7,9,11,15,17]$. Cotton states the success in this 'secondary' group is influenced by the imprevement in pulmonary function that occurs with increasing age [2].

Cotton and Seid have gone on to outline specific criteria for the use of the anterior cricoid split [3]. Neonates ready for extubation with subglottic pathology in whom the alternative would be a tracheotomy are candidates. However, extensive giottic pathology was a contraindication. The criteria have been broadened to include young infants. The oldest child in Cotton's series was 28 months old [2]. Infants with glottic pathology bave aiso been sxtubated. This may be the result of a change in the actual procedure, extending the incision through the anterior commissure superiorly to within $2 \mathrm{~mm}$ of the thyroid notch instead of splitting just the cricoid and upper two tracheal rings.

Holinger has outlined several mechanism: which may be responsible for the success of the anterior cricoid split [11]. Interruption of the cricoid cartilage decreases the pressure exerted by the endotracheal tube on the cricoid mucosa, restoring circulation and decreasing mucosal inflammation. Secondly, Holinger 
states that incision of the mucosa and other soft tissue within the lumen opens this tissue to drainage, including submucosal cysts. Thirdly, the inherent slasticity of tite cricoid cartilage allows it to "spring' opsic after being split resulting in ant increascod intralumenal surface area.

Hawkins [10] discusses the resilency of the neonate's carilage. Embryonic cartilage is hypercellular with little intervening matrix. With growh, the matrix increases in amoun: and the composition changes. There is a decrease in water content and more fibrous tissue is present. thus the cartilage is more rigid.

We postulate that the cricoth jroid muscle may play a role in the 'springing' open of the divided cricoid cartilage and the persistent open configuration. The orientation of the cricothysoid muscle predicts that the sut ends of the cricoid cartilage vould be pulled laterally, superiorly and posteriorly. Tiais action bilaterally tends to separate the cut ends of the cricoid cartilage and therefore maintair its open paxition.

An excellent carine model to study the mechanisms of acquired subglottic stenosis was developed by Supance el a:. [19]. A short segment of endotracheal tube was placed eadoscopically into th. laryngotracheal coruplex. After 7 days of intubation, minimai and reversio je subglotic disease is present whereas after 14 days, the subglottic injury produced ultimately resultzi in a mature cicatricial subglottic stenosis.

We were able to confirm the findings of Supance et al. [19]. Seven cays of intubation in our anima's produced a mildly injured laryagotracheal compler, whereas 14 days elicited a much more intense reaction. Performing the antenior cricoid split after 7 days of intubation not only prevented the progression of subgloftic injury from intubation, but essentially allowe, the subglottis to return in a nearly normal status.

The cricoid cartilage 'sprung' open in each of the animals in which the anterior cricoid split was performed. The elastic nature of the puppy cartilage along with tine action of the cricothyroid muscle contributes to this action. The cricoid cartilage opened even if the endotracheal tube was removed just prioi to splittiog he cartilage. The hypercellular nature of this immature cartilage accounts for its plasticity whereas older cartilage is less cellular, more fibrous and more rigid. We pestulate that the cricothyroid muscle may play a , ole in distracting the cut ends of the cricoid cartilage.

The animais in Group III gave us the opportunity to accurately measure the acute increase in intralumenal surface area seen by performing the auterior cricoid split. The curface area within the cricoid cartilage was increased by an average of 26\%. This increase dces not take into acc yunt the added increase in surface area that results from the expested resolution of mucusal edema and granulation tissue.

Within 3 weeks of performing the anterior cricoid split, the lumen of the cricoid was re-jpitinelialized. At no point post-operatively was there evidence of collapse at the site of the split and no long term complications from the anterior cricoid split were appreciated.

At full maturity, twe cricoid cartilage maintained the ' $U$ ' configuration. Thick, fibrous tissue bridged the gap between the cut ends of the cricoid. Fistologically, 
functionally and grossly, the cricoid cartilage matured in a normal fashion in the aitimals in which the cricuid split had been perfornoed.

\section{Acirmowledgements}

The authors wish to thank Doris Tolford for her secretarial assistance in prepa jng the manuscript and Dr. Kenneth McClktshey for reviewing the histopathology.

\section{References}

1 Caldwell, C.C., Stankeiwicz, J., Anderson, C.L., Ahmed, G.S. anj Nicyers, T.F. Intubation - related tracheal stenosis in very - low - birth - weight Infarts, Am. J. Dis. Child., 130 (1585) 618-620.

2 Cotton, R.T., Prevention and manageraent of laryngeal stenosis in inforis and children, Pediatr. Surg, 20 (1985) 845-851.

3 Coiton, R.T. and Seid, A.B., Manogement of the extubation prob':m in the premature child: anterior cricoid split as an alvercative to iracheotomy, Ann. Otol. Rhinol. Laryngol., 89 (1980) 508-51..

4 Dankle, S.K., Schulier, D.E. and McClead, R.E., Risk factors for neonatal subglottis stenosis, Ann. Otol. Risinol. Laryngol., 95 (1986) 626-630.

5 Fearon, B. and Ellis, D., The management 0. losestim airway problems in irfants ard childrer, Ann. Otol. Rhinol. Laryngol, 80 (1971) 6i்7-669.

6 Fishmar, R.A. and Pasiley, N.F.T., A study of the premature nexosutal airway, Utolaryngol. R:=idu Neck Surg., 89 (1981) 604-607.

7 Franke!, L.R., Aras, N.G. Perkin, P.M., Sei ', A.B., Pettison, B. and Park, S M., Use of the anterio: criooid spot oferatios in infants with acquired subglottic stenosis, Crit. Care Med., 12 (1984) 395-398.

8 Gaudest, P.T. Paerle is, A., Sasaki, C.T. et al., Pediatric tracheostomy and associated complicutions, Laryngosiespe, 88 (1978) 1633-1 441.

9 Grundfast, K.M., Coffman, A.C and Milmoe, G., Anterior cricoid split: a "simple" surgical proceriure and a potentially complicated care problera, Ann. Otol. Rhinol. Laryngol., 94 (1985) 445-.449.

10 Hewkins, D.B., Hyaline membrane disen se of the neonate. Prolonged in tubation in the management: iffects on the larynx, Laryngoscope, 88 (1978) 201-224.

11 Holinger, L.D., Stankiewicz, J.A. and Livingston, G.L., Anterior cricoid split: the Chicago experience with an alternative to tracheotomy, Laryngoscope, 97 (1987) 19-24.

12 Lindholm, C.D., Prolonged endotracheal intubation, Acta. Anaesthesiol. Scand., Suppl. 33 (1969).

13 Marshak, G. and Grundfast, K.M., Subglottic stenosis, Pediatr. Clin. Nurth Am., 28 (1981) 941-948.

14 McDonald. I.H. and Stocks, J.G., Prolonged nasotracheal intubation, Brit. J. A.r.susthesiol., 37 (1965), 161-172.

15 Miller, R.H. and Weatherly, R.A., Experience with anterior cricoid split for difficult neonatal extubatiun, Arch. Otolaryngol. Head Neck Surg., 112 (1986) 972-975.

16 Parkin, J.L., Stevens, M.H. and Jung, A.L., Acquired and congenital subglottic stenosis in the infant, Ann. Otol. Rhinol. Laryngol., 85 (1976) 573-581.

17 Pashley, N.R.T., Anterior cricoidotomy of congenital and acquired subglottic stenosis in infants and children, J. Otolaryngol., 13 (1984) 187-190.

18 Ratner, I. and Whitfield, J., Acquired subglottic stenosis in the very - low - birth - weight infant, Ant. J. Dis. Child, 137 (1983) 40.43.

19 Supance, J.S., Reilly, J.S., Doyie, W.J., Bluestone, C.D. and Hiubbari, J., Acquired subglottic stenosis following prolonged endotracheal intubation, Arch. Otolaryngol., 108 (1982) 727. 7,31. 